\title{
Finite Element Analysis and Tooth Profile Modification Study on Traction Gear of High Speed and Heavy Load Locomotive
}

\author{
Xiaochun $\mathrm{Shi}^{*}$ and Weidong He \\ Mechanical Engineering Department, Dalian Jiaotong University, Dalian 116000, China
}

\begin{abstract}
Base on the characteristics of high-speed and heavy-load locomotive traction gear, a pre-grinding hob was designed which increased the thickness of the dangerous tooth root section as much as possible. The deformation and stress of the traction gears were calculated through the parameterized model established by finite element method. The tooth profile modification was implemented considering three locomotive working conditions including starting, sustain, and rapid operation. Finally, the related tests verified that the optimized transmission gear was in accordance the design requirements, the effect was good.
\end{abstract}

Keywords: Finite element analysis, gear tooth profile modification, locomotive traction gear, test.

\section{INTRODUCTION}

Locomotive traction gear is located between the motor and wheels of the locomotive, driven by the traction motor. It is the most core part of locomotive running gears, usually made of cylindrical gear. It transfers the movement and force of the locomotive in the running process, and its structures are shown as Fig. (1) [1].

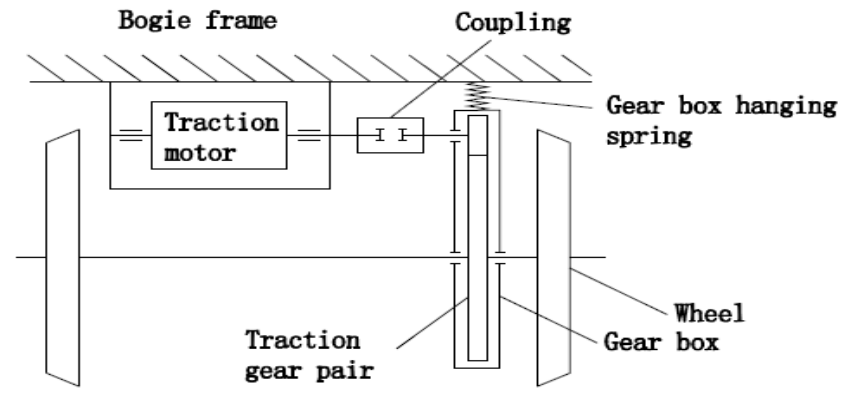

Fig. (1). Working principle diagram of traction gear.

Along with the development of high-speed railway, the integration level and complexity of the locomotive traction institutions have been improving continually, so the power of the traction gear continues to be enhanced, therefore its working time has been continuously increasing and traction tonnage is also rising. However, at the same time, in the working process, it has to bear the random loads, serious unbalance loads and the vibrations caused by the different operations and service conditions are very bad. A type of traction gear, as shown in Fig. (2), its teeth are badly worn and scrapped due to running for about 600000 kilometers. The consequence is that the life of the locomotive traction gear cannot meet the needs of current and future high-speed rail development. Therefore, the design and processing of the

*Address correspondence to this author at the Mechanical Engineering Department, Dalian Jiaotong University, Dalian 116000, China;

Tel: 15841153528; E-mail: shilinkang@sina.cn traction gear have earned great importance both at home and abroad. How to improve the bearing capacity and service life of the traction gear, and which are in dire needed to be solved urgently.

Base on the thorough analysis of the characteristics of various kinds of traction gear transmission systems of the locomotives, with a certain type of locomotive traction gear as an example, this paper has carried out the research from several aspects as follows: the design of the gear pregrinding hob, the analysis and calculation of tooth surface contact stress and tooth root bending stress, the gear tooth profile modification and so on.

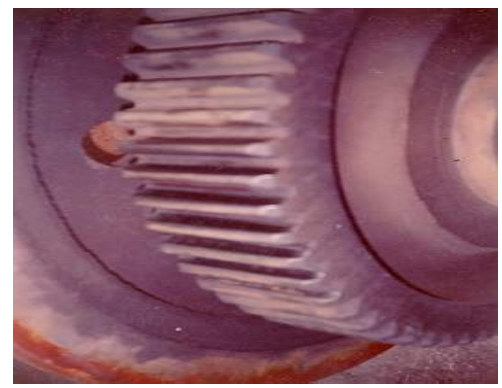

Fig. (2). Tooth surface failure.

\section{THE DESIGN OF THE GEAR PRE-GRINDING HOB}

Roll-grinding process is usually used in processing highspeed, heavy-load, large modulus traction gears, and there are two kinds of pre-grinding hob: double-arc pre-grinding hob and the single-arc pre-grinding hob (As Fig. 3). The bending stress at tooth root part is higher when the traction gear works. Practice shows that the main reason for the damage of gears is the insufficient bend fatigue strength, therefore, the single-arc grinding hob is more commonly used to process the gears, as it can increase the tooth root fillet and reduce the stress concentration [2], at the same time, it also increases the dangerous cross section thickness 
and improves the tooth root bending fatigue strength and impacting on resistance significantly. In addition, the tip clearance also has an important effect on transmission quality, so in the process of design, the addendum height of cutting tool should be strictly controlled (Table $\mathbf{1}$ ).

Table 1. Basic parameters of certain locomotive traction gears.

\begin{tabular}{|c|c|c|}
\hline Name/Symbol & Value & Units \\
\hline \hline Teeth numbers of driving gear/z $\mathrm{z}_{1}$ & 16 & \\
\hline Teeth numbers of driven gear $/ \mathrm{z}_{2}$ & 91 & \\
\hline Helical angle/ $\beta$ & 6 & $\mathrm{deg}$ \\
\hline Unilateral grinding amount $/ \mathrm{w}$ & 0.26 & $\mathrm{~mm}$ \\
\hline Modulus of elasticity $/ \mathrm{E}$ & 206 & $\mathrm{GPa}$ \\
\hline The modulus $/ \mathrm{m}_{\mathrm{n}}$ & 9.5 & $\mathrm{~mm}$ \\
\hline Tip clearance coefficient $/ \mathrm{Cn} *$ & 0.35 & \\
\hline Addendum coefficient $/ \mathrm{han} *$ & 1 & \\
\hline Poisson's ratio $\mu$ & 0.3 & \\
\hline Tooth width $/ \mathrm{B}$ & 130 & $\mathrm{~mm}$ \\
\hline
\end{tabular}

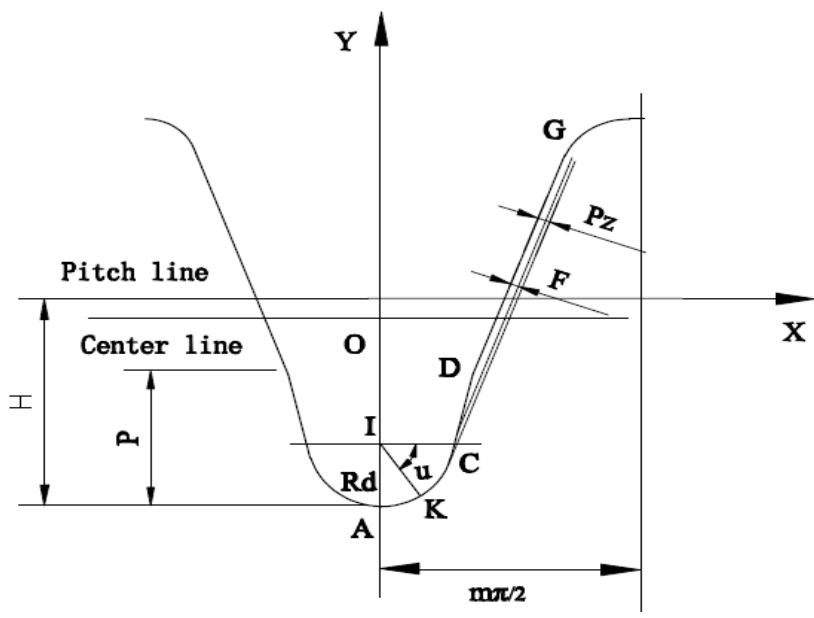

Fig. (3). The normal tooth profile of a pre-grinding hob with singlearc.

In order to ensure strong tooth root bending strength, anti-bonding capability, and the thickness of the tooth root, the pressure angle of the primary cutting edge is taken 23.5 degrees, i.e., the standard traction gear pressure angle $\alpha_{\mathrm{n}}$. Studies shows that the greater the main blade profile angle is, the larger is the side edge relief angle, the higher is the service life of cutting tools. Therefore, in the design process, the transition edge profile angle is increased and the value is taken as 14.5 degrees.

(1) In order to ensure the thickness of cutting tool, and ensure the effective length of involute, the limit thickness of the pitch circle of the tools is designed:

$\mathrm{S}_{\mathrm{n}}=\frac{\pi \mathrm{m}_{\mathrm{n}}}{2}+2\left(\mathrm{~A}_{\max }+\mathrm{w}\right) /(\cos \alpha)$
(2) In order to guarantee the tip clearance, the biggest tip radius is designed:

$R_{d}=\left(\frac{S_{n}}{2}-h_{a} \tan \alpha\right) /[\tan (90-\alpha) / 2]$

where: $A_{\max }$-the smallest deviation of the common normal line, determined by the machining precision of the gear; $h_{a}$ the addendum height of the tool.

\section{ESTABLISHMENT OF THE FINITE ELEMENT MODEL OF TRACTION GEAR}

The involute helical cylindrical gears are usually used in locomotive traction gear transmission. Due to their larger contact ratio and stable mesh performance, they are particularly applicable to high-speed and severe-duty drive.

With the development of computer technology, the accurate simulation of the strength of gears has become possible in the process of gear design, and by virtue of its fast and flexible features, the method has been widely used. This paper intends to use the design language APDL in ANSYS and complete the parametric modeling of helical gears cut by a single-arc pre-grinding hob $[3,4]$.

\subsection{The Formation of Involute}

As shown in Fig. (4), when the line NK make pure roll along the circle with radius $\mathrm{r}_{\mathrm{b}}$, the trajectory of arbitrary point $\mathrm{K}$ on this line is the involute of the circle and the main profile of helical gear tooth is a part of it [5].

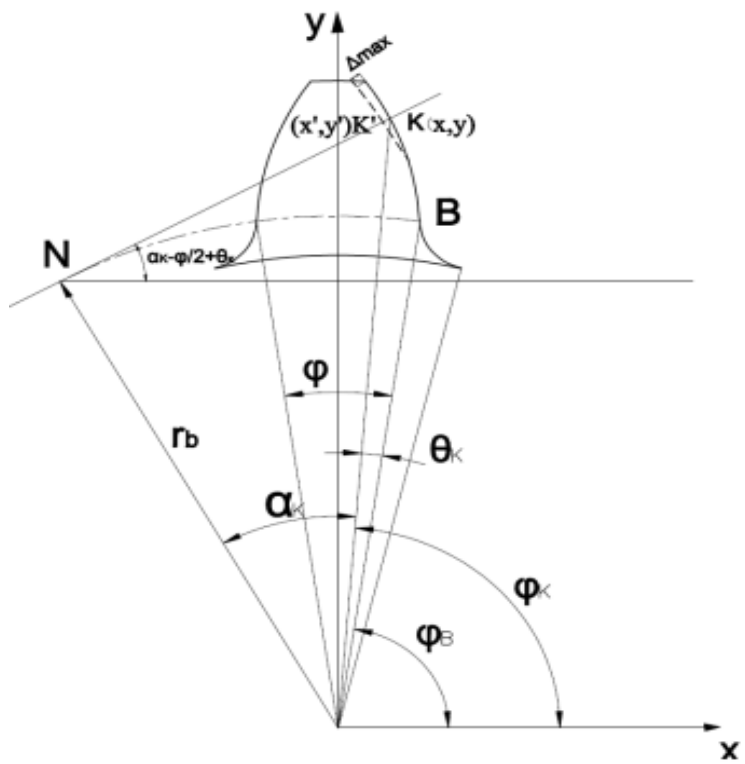

Fig. (4). The standard tooth profile and the modified tooth profile.

The rectangular coordinates equations of main involute can be obtained as:

$\left\{\begin{array}{l}\mathrm{x}=\frac{\mathrm{r}_{\mathrm{b}}}{\cos \alpha_{\mathrm{k}}} \cos \left(\phi_{B}+\theta_{K}\right) \\ y=\frac{\mathrm{r}_{\mathrm{b}}}{\cos \alpha_{\mathrm{k}}} \sin \left(\phi_{B}+\theta_{K}\right)\end{array}\right.$ 
The relational expressions in the equations:

$\theta_{K}=\operatorname{tg} \alpha_{K}-\alpha_{K}$

$\phi_{B}=\pi / 2-\phi / 2$

$\phi_{K}=\phi_{B}+\theta_{K}$

According to the involute equation, $\alpha_{\mathrm{K}}$ as the independent variable (its range changes from 0 to $\alpha_{\mathrm{a}}, \alpha_{\mathrm{a}}$ is the addendum circle pressure angle), a series of keypoints can be obtained by setting the steps and linking them with smooth spline curve, from which the involute can be formed.

where: $\mathrm{r}_{\mathrm{b}}$-the base circle radius; $\alpha_{\mathrm{k}}, \theta_{K}$-the pressure angle and the generating angle of the involute in point $\mathrm{K} ; \phi_{B}, \phi_{k}$ the polar angles in the point $\mathrm{B}$ (the starting point of the main involute )and arbitrary point $\mathrm{K}$ on the base circle; $\phi$ the circumference angle corresponding to the tooth thickness of base circle.

\subsection{The Formation of Tooth Root Transition Curve}

The tooth root transition curve is an extending involute equidistant curve, processed by the top circular arc of the pre-grinding hob. The relationship between them is shown in Fig. (5). The coordinate of the arbitrary point $\mathrm{K}$ (point $\mathrm{K}$ is on the top circular arc AKC of the pre-grinding hob)in the coordinate system 1 converts to the coordinate system 2 , the equations of tooth root transition curve can be obtained. According to the transfer principle of coordinate transformation $[6,7]$ :

$\left[\begin{array}{l}x_{2} \\ y_{2} \\ t_{2}\end{array}\right]=\left[\begin{array}{ccc}\cos \phi & -\sin \phi & r \phi \cos \phi-r \sin \phi \\ \sin \phi & \cos \phi & r \cos \phi+r \phi \sin \phi \\ 0 & 0 & 1\end{array}\right] \cdot\left[\begin{array}{c}x_{1} \\ y_{1} \\ t_{1}\end{array}\right]$

By Concluding Fig. (5), the equations of $x_{1}, y_{1}$ are:

$\left\{\begin{array}{l}\mathrm{x}_{1}=R_{d} \cos u \\ y_{1}=-b+R_{d}(\sin \alpha-\sin u)\end{array}\right.$

Taken (8)into (7) and get:

$\left\{\begin{array}{l}\mathrm{x}_{2}=\left(R_{d} \cos u+r \phi\right) \cos \phi+\left[b-R_{d}(\sin \alpha-\sin u)-r\right] \sin \phi \\ y_{2}=\left(R_{d} \cos u+r \phi\right) \sin \phi+\left[-b+R_{d}(\sin \alpha-\sin u)+r\right] \cos \phi\end{array}\right.$

In order to ensure the normal line of contact points, the pitch point $\mathrm{P}$ shall be passed and this equation must be met:

$\operatorname{tg} u=\frac{b-R_{d} \sin \alpha}{r \phi} ;$

Among the equations: b-the distance between the tip circle center of the hob and the pitch line; r-the pitch circle radius; $u$-the included angle formed by the normal through arbitrary point $\mathrm{K}$ and the pitch line, range $[0,90] ; \phi$-the hob rotating angle relative to the gear at any position.

A series of keypoints can be obtained by setting the steps and linking them with smooth spline curve and forming the tooth root transition curve.

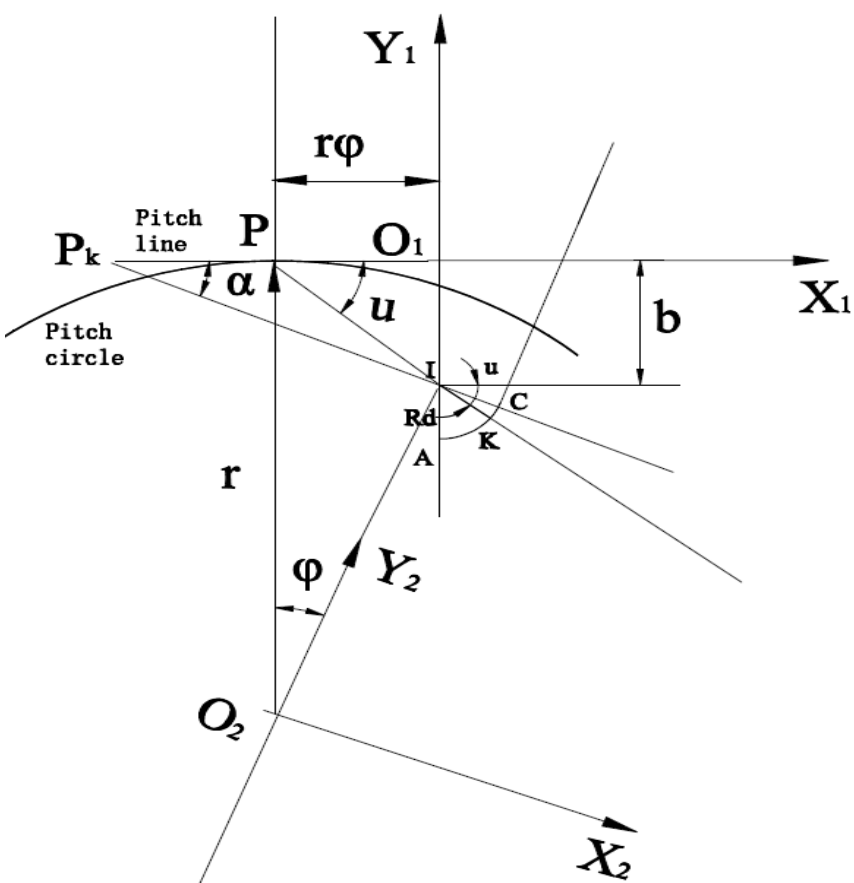

Fig. (5). The coordinate conversion of tooth root transition curve.

The helical cylindrical gear transmission, due to the existence of the spiral angle, has the transverse contact ratio and axial coincidence degree. In the working process, load is often shared by many teeth, therefore the finite element model with more teeth meshing is established base on the coincidence degree. The spiral angle is very small in this model, the coincidence degree doesn't exceed than 2, so three teeth are chosen to establish finite element model [8], as shown in Fig. (6).

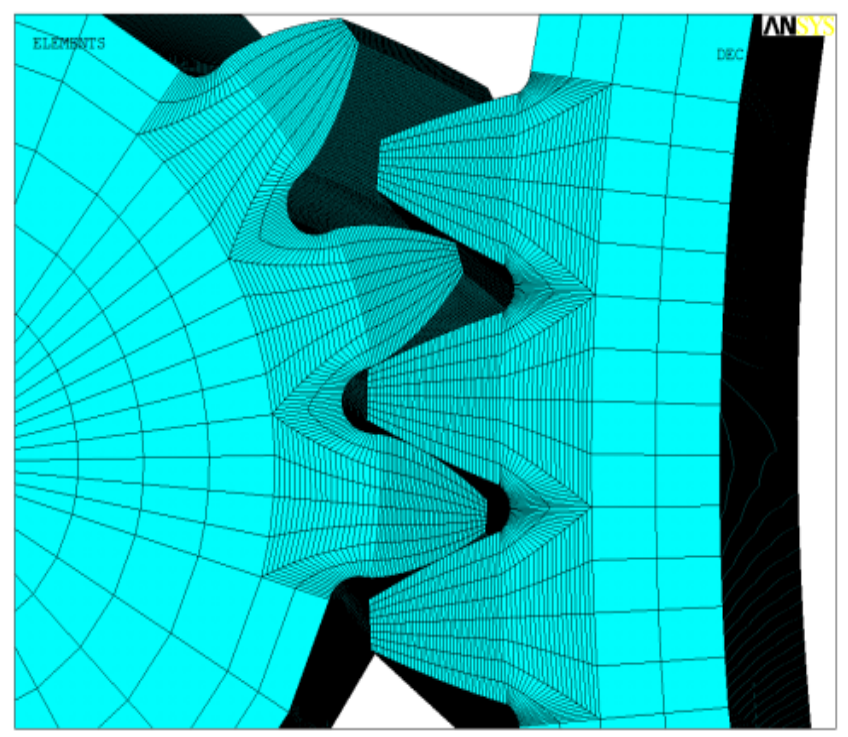

Fig. (6). Three-dimensional gear contact finite element model.

\section{ESTABLISHING THE BOUNDARY CONDITIONS FOR THE FINITE ELEMENT MODEL OF TRACTION GEARS}

Before the finite element analysis for the gear model, the elements should be set, the contact elements should be 
chosen, and the boundary constraints and loads should be added.

\subsection{The Choice of the Elements}

SOLID45 is generally used for 3D solid modeling, an eight-node hexahedral element; SOLID185 is similar to SOLID45, but has the capacity for analyzing super-elastic, large deformation and large strain, and can also simulate 3D composite; SOLID95, SOLID186 are the higher versions of SOLID45, SOLID185, they are twenty-node hexahedral elements, having secondary displacement function, especially for meshing curved surface, but they require larger computer memory and a lot of computing time.

For Comprehensive consideration, this paper chooses element SOLID185 to establish 3D finite element contact model for the traction gears.

\subsection{Selection of the Contact Elements}

Contact between the teeth exhibits a highly nonlinear behavior, the contact behavior can be identified through designated contact elements. In this paper, for the purpose of contact problem of gears, the elements TARGE170 and CONTA173 are adopted to simulate the 3D target surface and contact surface. The friction coefficient of the contact models is 0.1 [9].

\subsection{Adding the Boundary Constraints and Loads}

The degrees of freedom of all the nodes in inner ring of the big gear are constrained. The pinion is driven by torque $\mathrm{T}$ in the circumferential direction in the cylindrical coordinate system, the radial and axial degrees of freedom of all the nodes in the inner ring of pinion are constrained, and its rotational degrees of freedom are retained, and the torque $\mathrm{T}$ is transformed into a tangential force on all the nodes in the inner ring [10]:

$\mathrm{F}=\mathrm{T} /(\mathrm{r} \times \mathrm{N})$ :

where: F-the average tangential force on the inner ring nodes; $\mathrm{r}$-the inner ring radius of the pinion; $\mathrm{N}$ - the total number of the nodes on the inner ring.

\section{STRESS ANALYSIS AND COMPARISON OF DIFFERENT CONDITIONS}

In the work process, locomotive traction gears need to adapt to different working conditions, therefore, it is worth to study how tooth stress is distribute under the variable conditions. In addition, the traction gear has two kinds of working states : the small gear is rotated clockwise (looking from the gear outside, named front Guide Surface), and the small gear is rotated anticlockwise (named back Guide Surface), the influence of the support structures is different for these two conditions, so the distribution of the load and stress is also different. Due to space relations, this paper is just based on three actual conditions of locomotive traction gear including starting, sustain and rapid operation for front Guide Surface (Table 2).

Because the contact ratio coefficient is less than 2, the gear engagement can be divided into two alternate processes: single teeth meshing and double teeth meshing. The upper bound point of single teeth meshing zone is the worst loading points, as in this location, only a pair of teeth is involved in the working, the tooth root bending stress being the maximum value. In the simulation calculation, the distribution of the tooth root bending stress is reflected by the first principal stress. The maximum value of contact stress will appear at the lower bound point of single teeth meshing zone and will be reflected by the contact pressure between the contact surface.

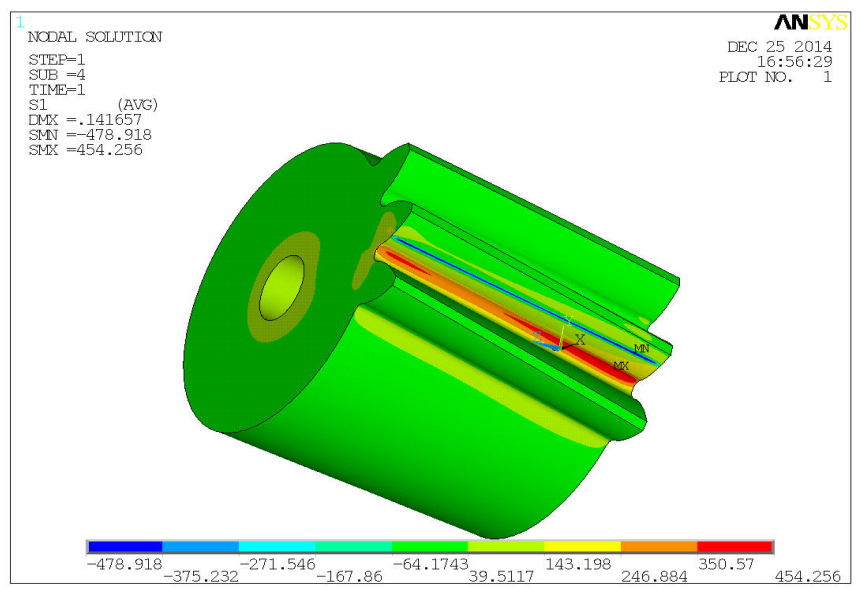

Fig. (7). The surface contact stress of starting operation.

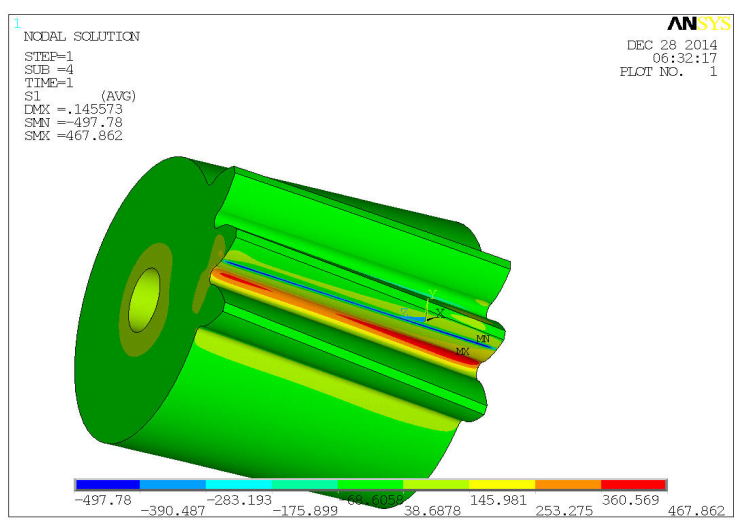

Fig. (8). The surface contact stress of sustain operation.

Table 2. The parameters of three actual operating conditions.

\begin{tabular}{|c|c|c|c|}
\hline Operating Conditions & Vehicle Speed (km/h) & Power (kw) & Motor Speed (rpm) \\
\hline \hline Starting Operation & 5 & 136.5 & 126 \\
\hline Sustain Operation & 18 & 500 & 460 \\
\hline Rapid Operation & 100 & 500 & 2500 \\
\hline
\end{tabular}




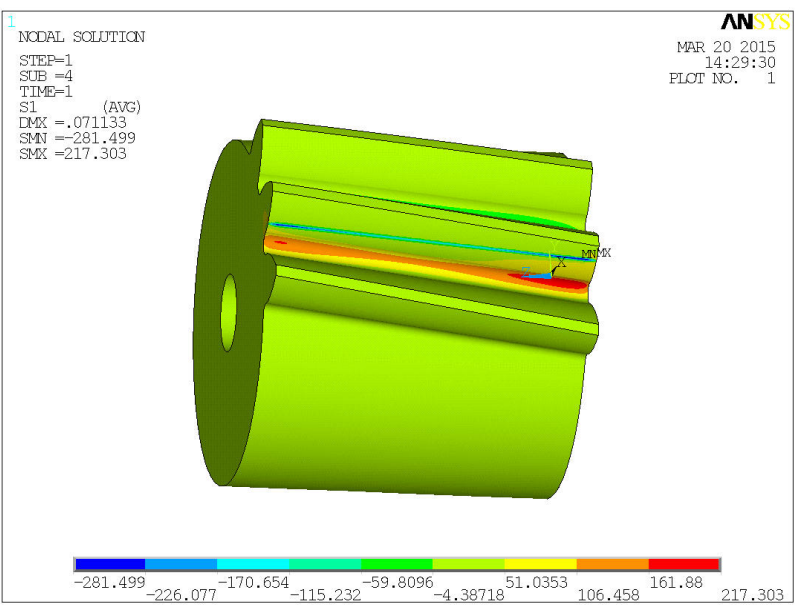

Fig. (9). The surface contact stress of rapid operation.

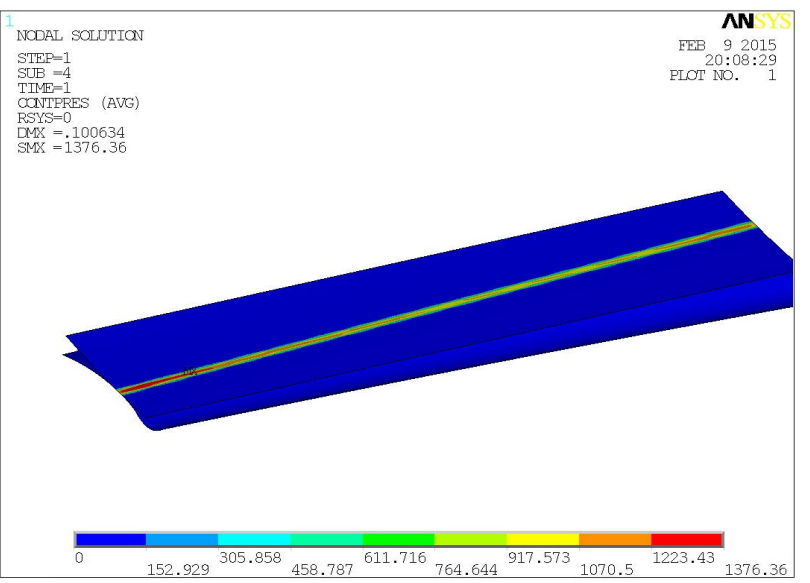

Fig. (10). The surface contact stress of starting operation.

Tooth root bending stress is shown in Figs. (7-9) and tooth surface contact stress in Figs. (10-12). The simulation results reflect, in these three operations, that the nominal load in sustain operation is better than starting operation, but under this operation, the computational load coefficient $\mathrm{K}$ is higher, so the calculated stress value is the highest of three operations. However, it is only slightly higher than the starting operation. The gears start working steadily in rapid operation, so the load is the least and the gear stress also decreases rapidly. The following analysis is based on the sustain operation.

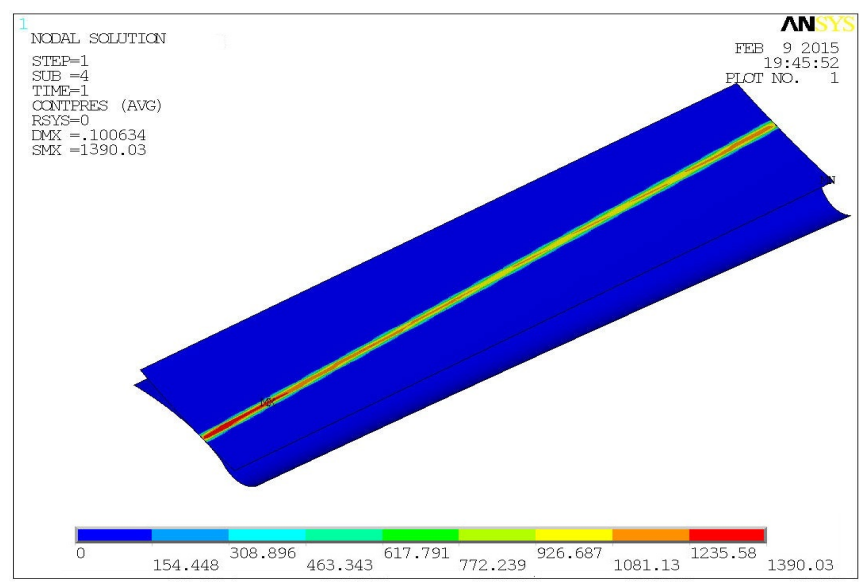

Fig. (11). The surface contact stress of sustain operation.

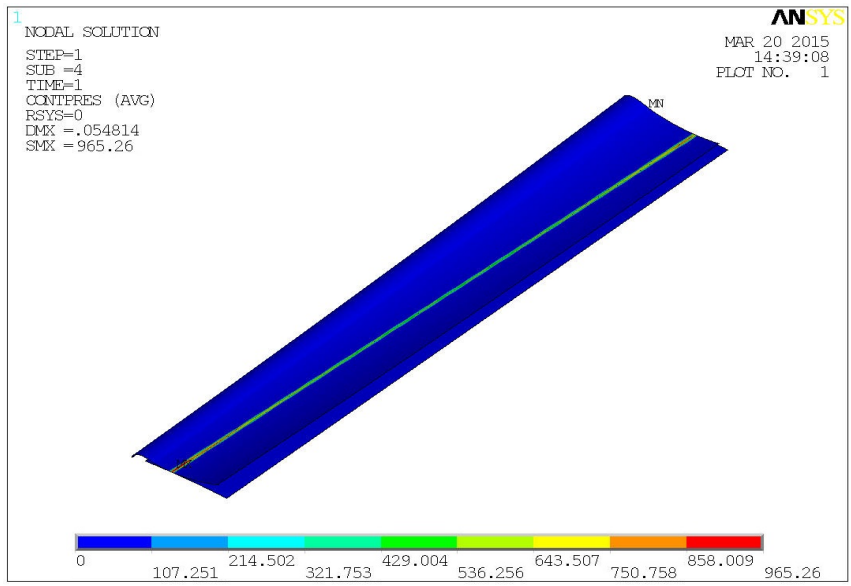

Fig. (12). The surface contact stress of rapid operation.

\section{GEAR TOOTH PROFILE MODIFICATION}

The gear engagement is an alternate process from single teeth meshing to double teeth meshing, as shown in Fig. (13). Theoretical load distribution is like AMNGHOPD, but due to the stress deformation during the gear engagement and the manufacturing and installation errors, the actual load distribution is like AEFGHIJD, load mutation has occurred in the transient process of single and double teeth meshing. The result is that the teeth elastic deformation is increased, the base pitch is changed and the engaging shock is intensified.

At the engaging-in position, as in Fig. (14a), in the engagement point $\mathrm{C}$, due to the elastic deformation of the teeth surface, gear teeth are subjected to bending and torsional deformation together, causing the actual base pitches of the driving and driven gears to change, which are no longer equal. The actual meshing line is no longer equal to the theoretic meshing line, so the top of the driven gear enters into engagement with the tooth root of the driving gear at point $\mathrm{A}$, producing interference and meshing impact at the engaging-out position, as shown in Fig. (14b), consequently the deformation at the contact point $\mathrm{B}$ will also result in meshing impact at point $\mathrm{D}$. The consequence is the changed instantaneous transmission ratio, generating scraping and impacting between the gear teeth. These are the main reasons for gear noises and dynamic loads.

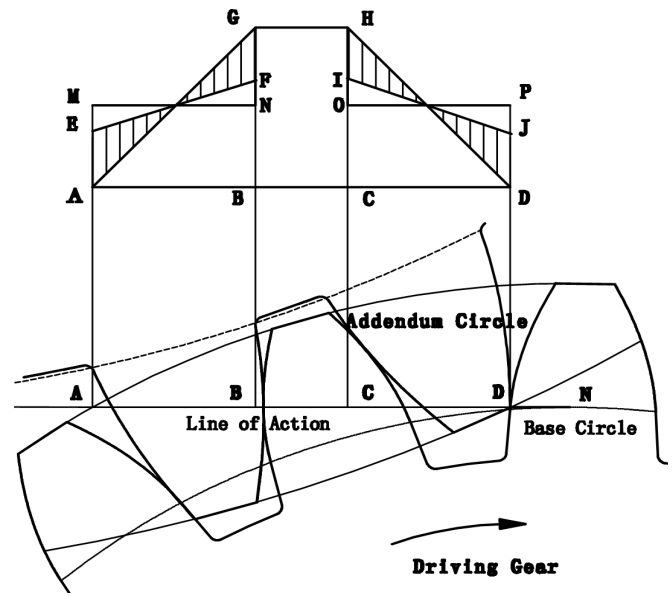

Fig. (13). Gear load distribution. 


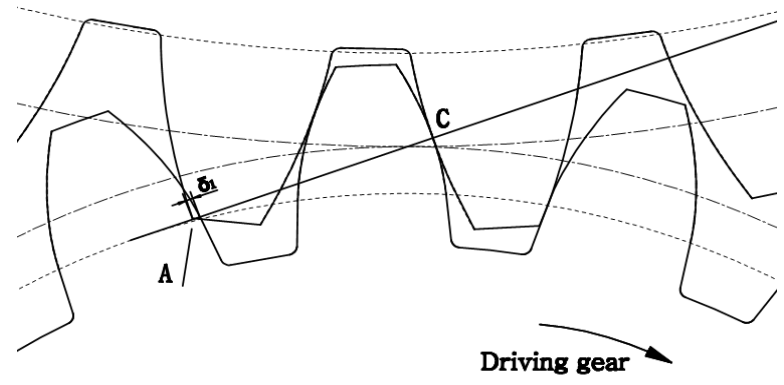

(a) Engaging-in impact caused by the driven gear addendum interference

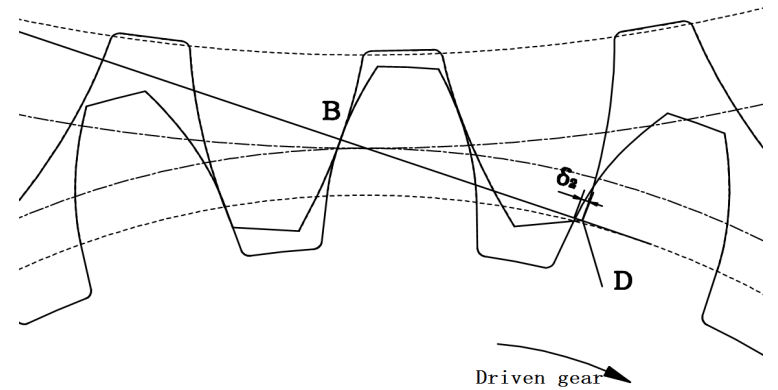

(b) Engaging-out impact caused by driving fear addendum interference

Fig. (14). Interference sketch of gear tooth.

From Fig. (15a-c), it can be seen the maximum stress is $1881 \mathrm{MPa}$ in the engaging-in position, the maximum stress is $2241 \mathrm{MPa}$ in the engaging-out position, both of them being the larger stress $1245 \mathrm{MPa}$ generated in the single teeth meshing zone (Fig. 15b). The results here fully verify the meshing impact produced in the engaging-in and engagingout position [11].

The main method to eliminate the meshing impact and decrease the vibration and noise is tooth profile modification. The need is just to determine three elements of modification, namely the maximum value of modification, length of modification and the curve of modification, through which modification can be completed.

\subsection{Determination of the Maximum Value of Modification}

According to the results of finite element analysis, shown in Fig. (16), it transforms the deformation of C, D points to coordinate system based on mesh surface, extracts the deformation of driving and driven gear along the meshing line direction(contains the tooth contact deformation and bend deformation after loading), superposes the deformation of the driving gear and the driven gear and takes an average. Interference value $\triangle_{1}$ and $\triangle_{2}$ can be obtained. The value of pinion's addendum modification is $0.058 \mathrm{~mm}$ at enter position, the value of the big gear's addendum modification is $0.06 \mathrm{~mm}$ at exit position.

\subsection{Determination the Length of Modification}

Length of tooth profile modification is divided into long modification and short modification. Long modification starts from the starting point or ending point of meshing to the starting point or ending point of single tooth meshing region; Short modification starts from the starting point or ending point of meshing, and the length is half of the long modification. Corresponding to the loads generating the maximum value of modification, long modification rotary error is less than the short modification. In this paper, the gear is in full load condition for a long time, so the long modification is used. At the same time in high speed and heavy load condition, in order to prevent too much bending stress of tooth root generated, both the driving gear and the driven gear carry out addendum modification.

As shown in Fig. (17) [12], deduces the length of modification formula:

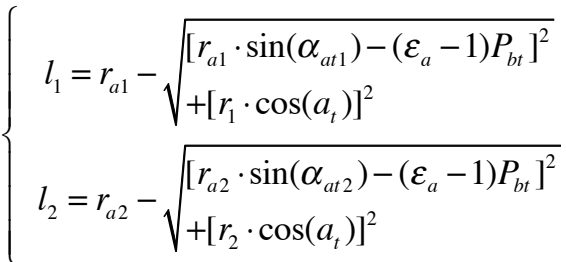

where: $r_{a}$--- the addendum radius; $P_{b t}$--- transverse base

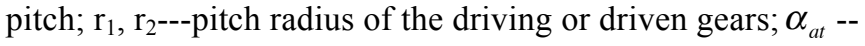

- transverse pressure angle at addendum circle; $\alpha_{\mathrm{t}}$--transverse pressure angle; $\varepsilon_{a}$--- transverse ratio.

\subsection{Determination the Curve of Modification}

The modification curve should be satisfied: in the exchange process of single and double teeth mesh region, load should have a smooth transition and a good process performance. Modification curve is commonly used with straight line, parabolic, circular arc curve, hyperbola and so on. This gear works under high speed and heavy load condition, the following modification curve is proposed to adopt:

$\Delta=\Delta_{\max }\left[0.44\left(\frac{x}{L}\right)+0.56\left(\frac{x}{L}\right)^{2}\right]$

where: $\Delta_{\max }$-the maximum value of modification; L-the length of modification;x-location of modification points on modification curve.

The coordinate relation formulas can be derived from Fig. (4) between point $\mathrm{K}^{\prime}\left(\mathrm{x}^{\prime}, \mathrm{y}^{\prime}\right)$ (any point on the modification curve) and point $\mathrm{K}(\mathrm{x}, \mathrm{y})$ (any point on the standard tooth profile):

Modification curve can be obtained according to the above formulas, as shown in Fig. (18). The maximum value of modification in Fig. (18) has been magnified 10 times in order to be examine conveniently.

$$
\left\{\begin{array}{l}
\mathrm{x}^{\prime}=\frac{\mathrm{r}_{\mathrm{b}}}{\cos \alpha_{\mathrm{k}}} \cos \left(\phi_{B}+\theta_{K}\right)-\Delta_{\max }\left[0.44\left(\frac{x}{L}\right)\right. \\
\left.+0.56\left(\frac{x}{L}\right)^{2}\right] \cdot \cos \left(\alpha_{k}-\frac{\phi}{2}+\theta_{k}\right) \\
y^{\prime}=\frac{\mathrm{r}_{\mathrm{b}}}{\cos \alpha_{\mathrm{k}}} \sin \left(\phi_{B}+\theta_{K}\right)-\Delta_{\max }\left[0.44\left(\frac{x}{L}\right)\right. \\
\left.+0.56\left(\frac{x}{L}\right)^{2}\right] \cdot \sin \left(\alpha_{k}-\frac{\phi}{2}+\theta_{k}\right)
\end{array}\right.
$$


(a) Engaging-in impact

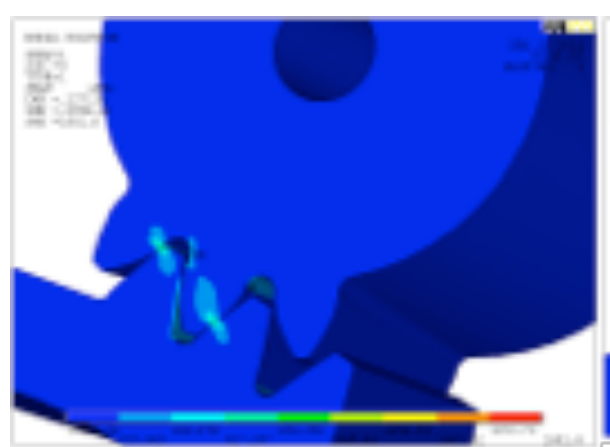

(b) Single teeth meshing area

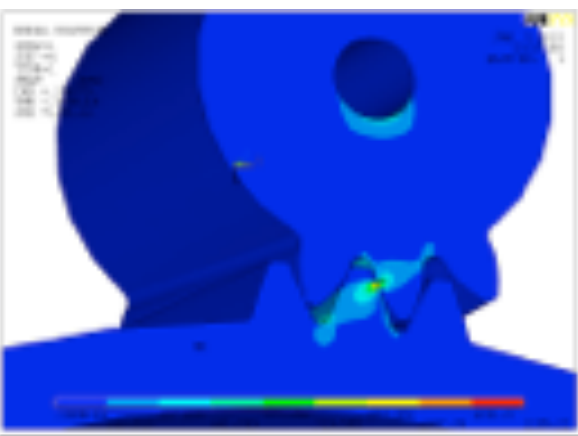

(c) Engaging-out impact

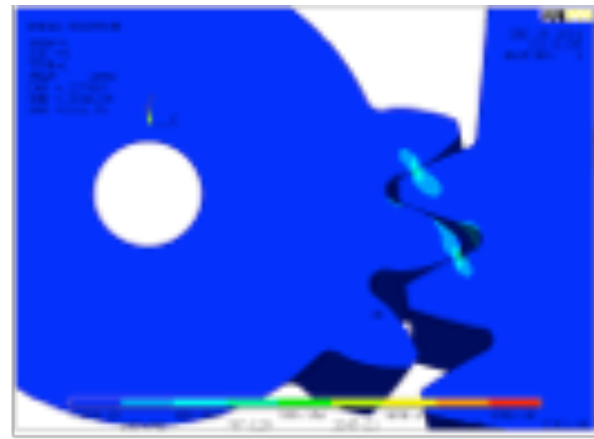

Fig. (15). Finite element analysis screenshots for the gear tooth interference.
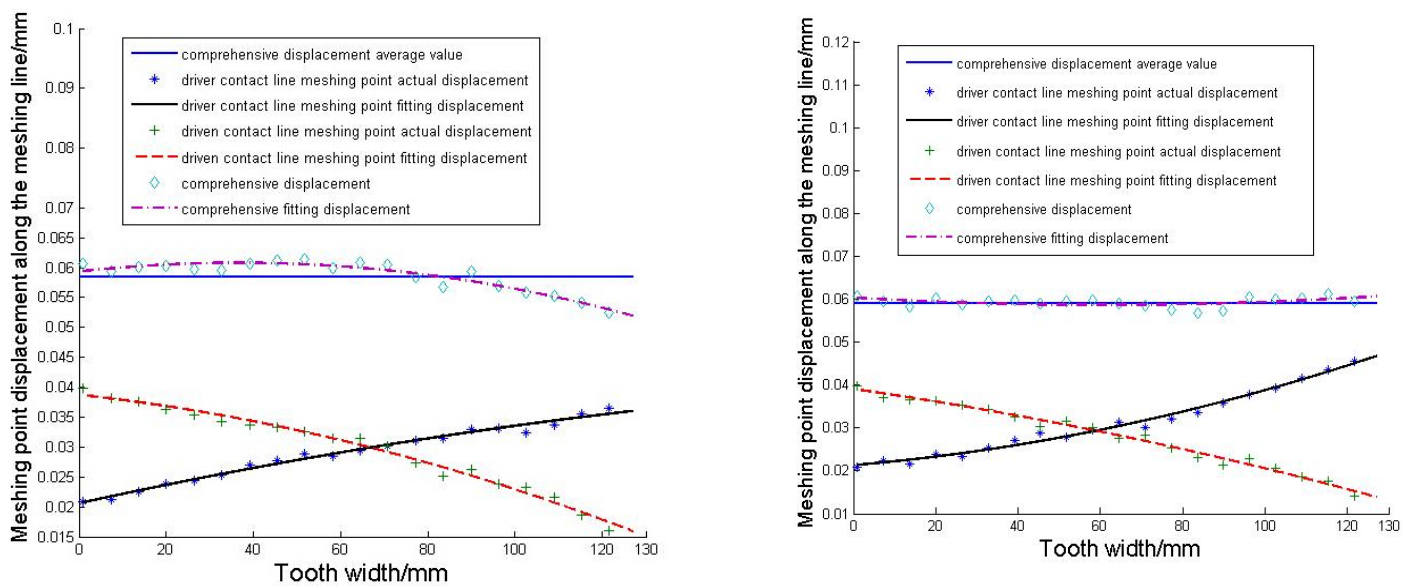

Fig. (16). The maximum amount of modification.

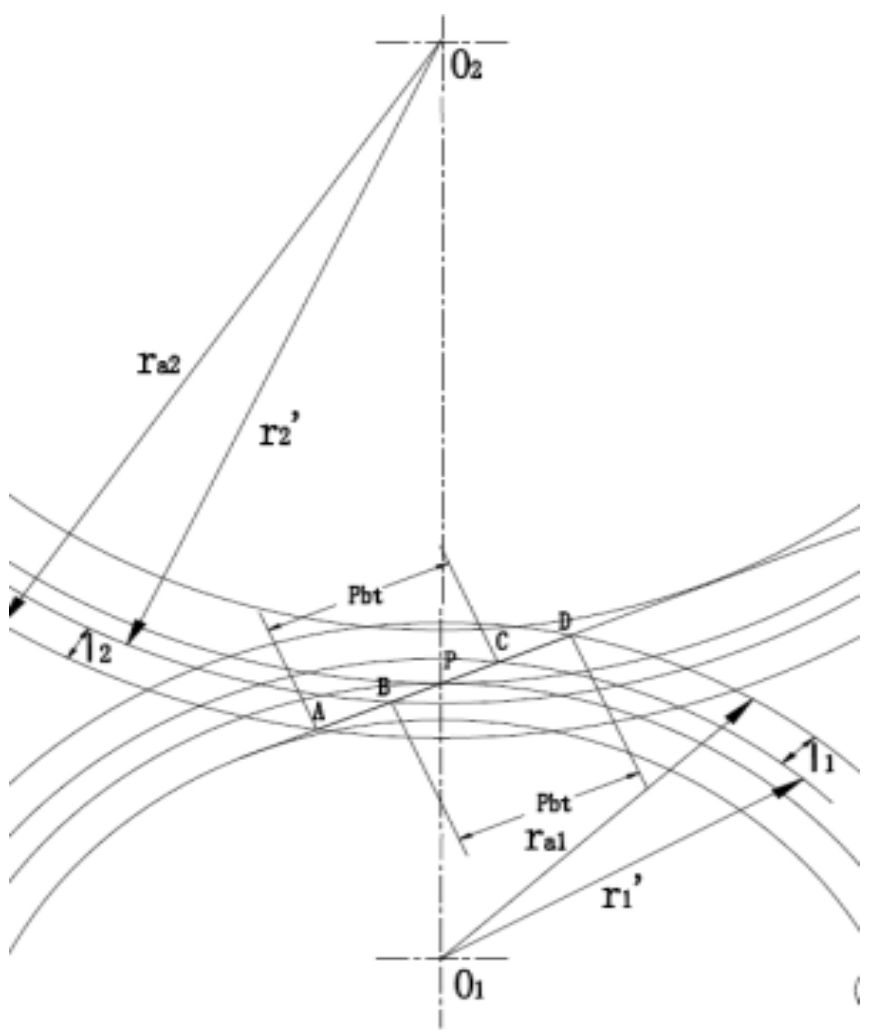

Fig. (17). The starting and end point of gear modification.

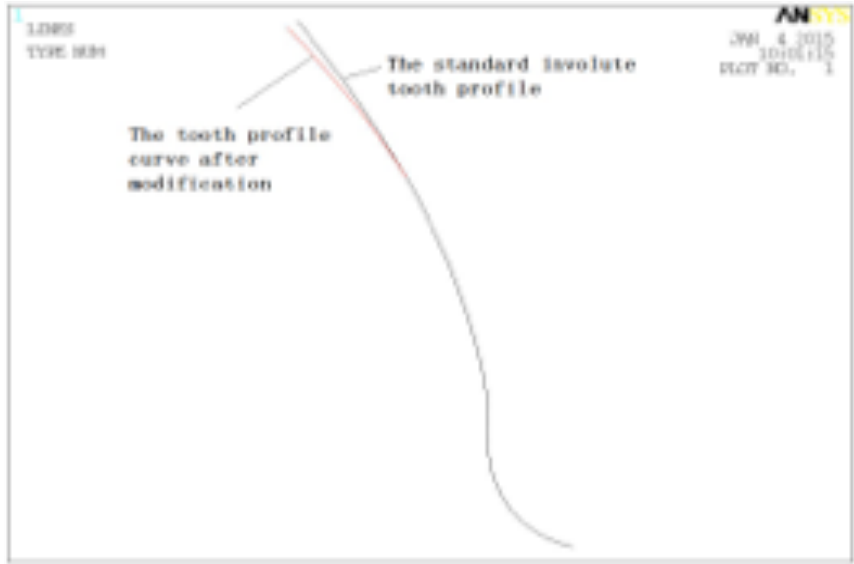

Fig. (18). Curve comparison before modification and after modification.

\subsection{Verification The Modification Effect}

Simulation analysis was carried out on the gear after modification, which showed that the stress decreased significantly at the engaging-in position and engaging-out position, as Fig. (19a, b). Stress at the engaging-in position is $1083 \mathrm{MPa}$, which decreased $42 \%$, and at the engaging-out position is $1167 \mathrm{MPa}$, decreased $47 \%$.

Fig. (20) shows the changes of contact stress in the meshing process of a pair of teeth. The red line graph represents the stress of standard profile curve, it can be seen 


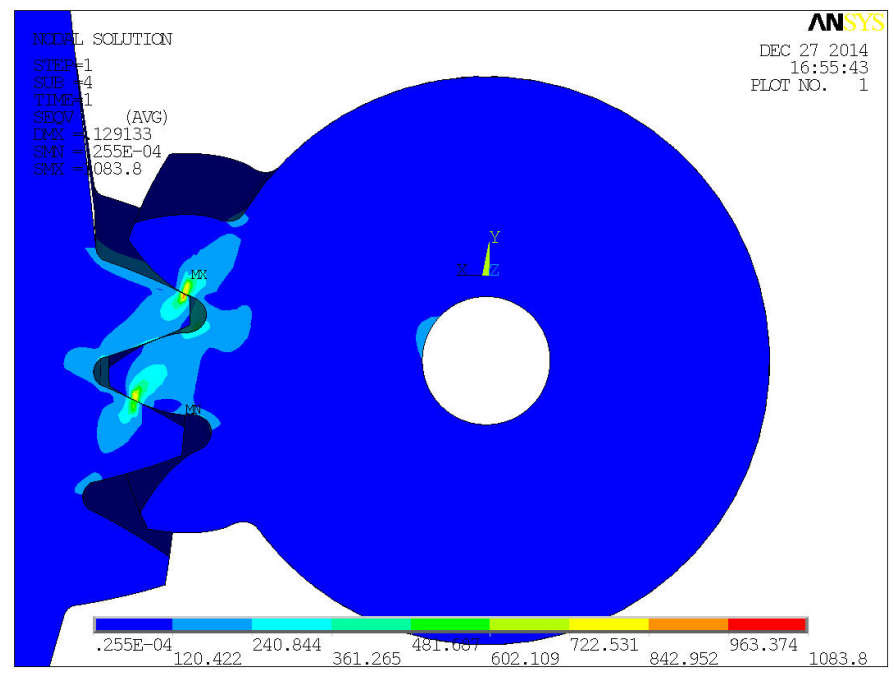

(a) Engaging-in position

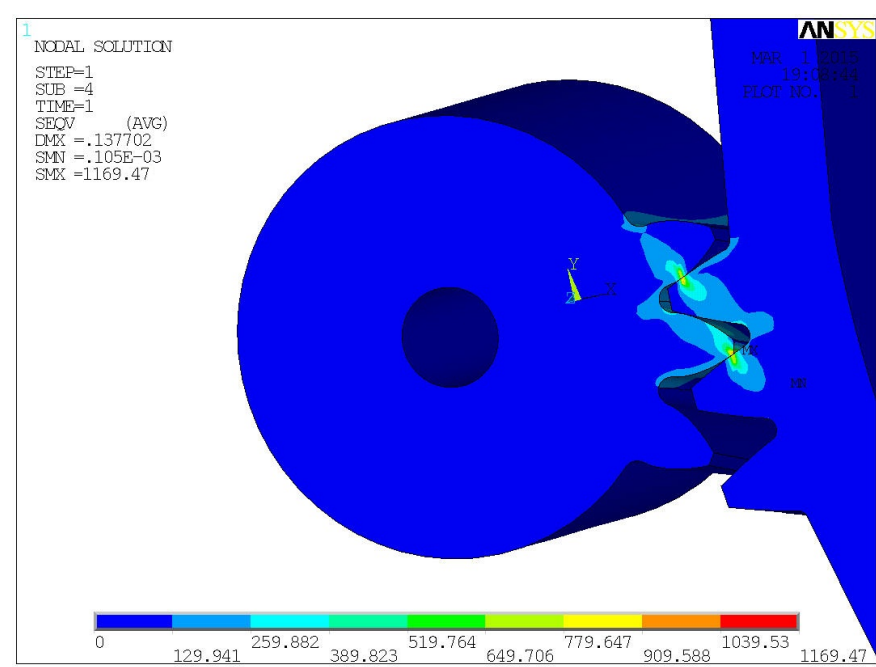

(b) Engaging-out position

Fig. (19). The finite element analysis results after modification.

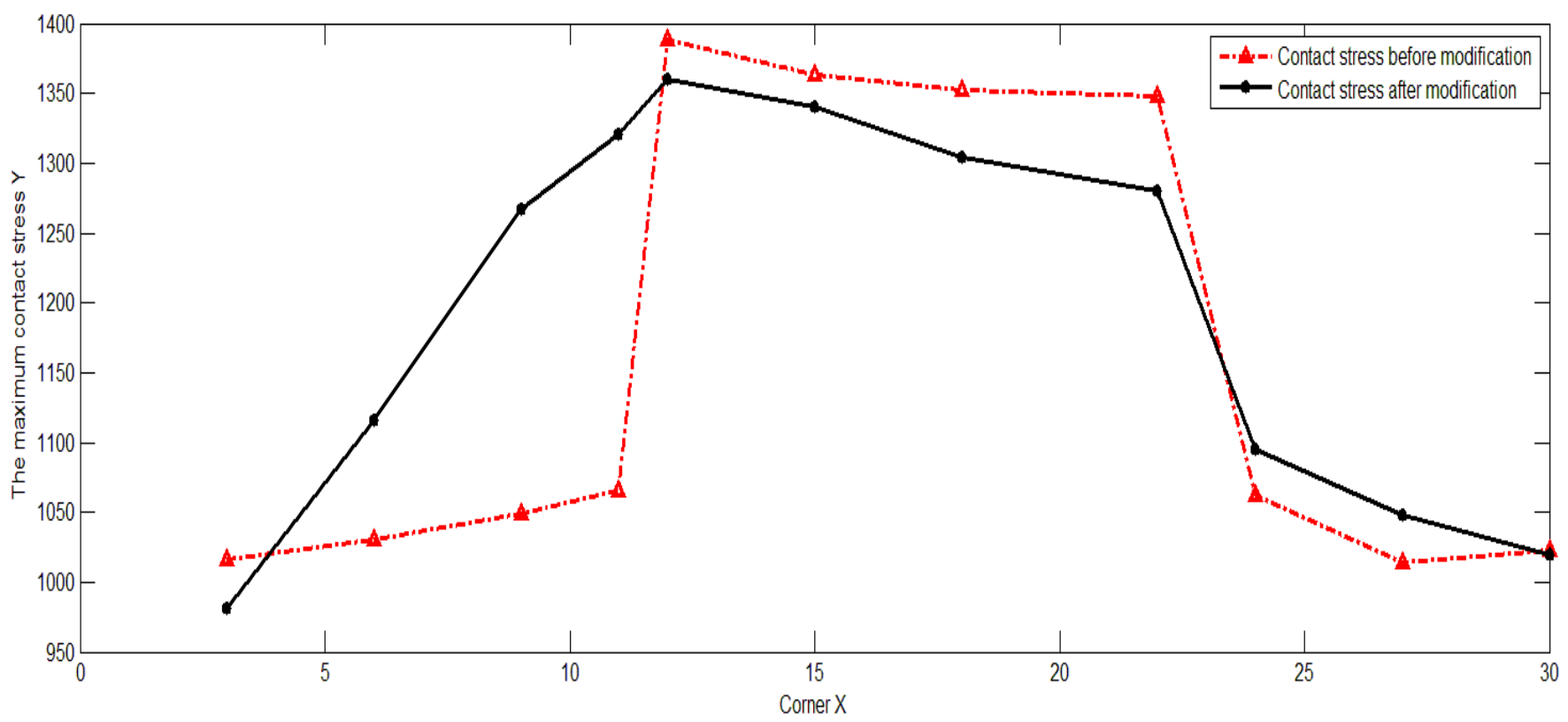

Fig. (20). Contact stress distribution curve before and after modification.

the load has obvious wave in the exchange process of single and double teeth mesh region, and after tooth profile modification, the contact stress is on the decline with the change being stable in the exchange process of single and double teeth mesh region, and there is no appearance of stress concentration phenomenon as black line.

\section{TEST}

In order to test the carrying capacity and verify the method correctness of the tooth profile modifications for the gear after optimization design, the carrying out of gear experimental study is very necessary. The carrying capacity of traction gear is measured by the test bench platform. The test platform is the hydraulic loading mechanical test bench using the internal helical gear transmission. The rotation speed of the motor is $140 \sim 2000 \mathrm{r} / \mathrm{min}$, the maximum load torque is $4000 \mathrm{~N} . \mathrm{m}$, and the closed power is up to $500 \mathrm{~kW}$.
On the test bench, the high-speed shaft rotation speed can be $360 \sim 5150 \mathrm{r} / \mathrm{min}$ after the speed increase by the paternity testing gearbox. The test bench can simulate the circumferential speed of high-speed locomotive traction gear transmission in the continuous operation process. At the same time, the shaft speed can be varied according to the need and the load can be changed by the internal helical gear hydraulic loader in operation. It can simulate three actual conditions of locomotive traction gear including starting, sustain and rapid operation. The test bench is shown in Fig. (21). Fig. (22) shows the optimized tooth face of locomotive traction gear after running 1,000,000 kilometers. The tooth surface is bright as a mirror and without any damage.

\section{CONCLUSION}

According to the traction transmission device characteristics of the high-speed and heavy-load locomotive, 


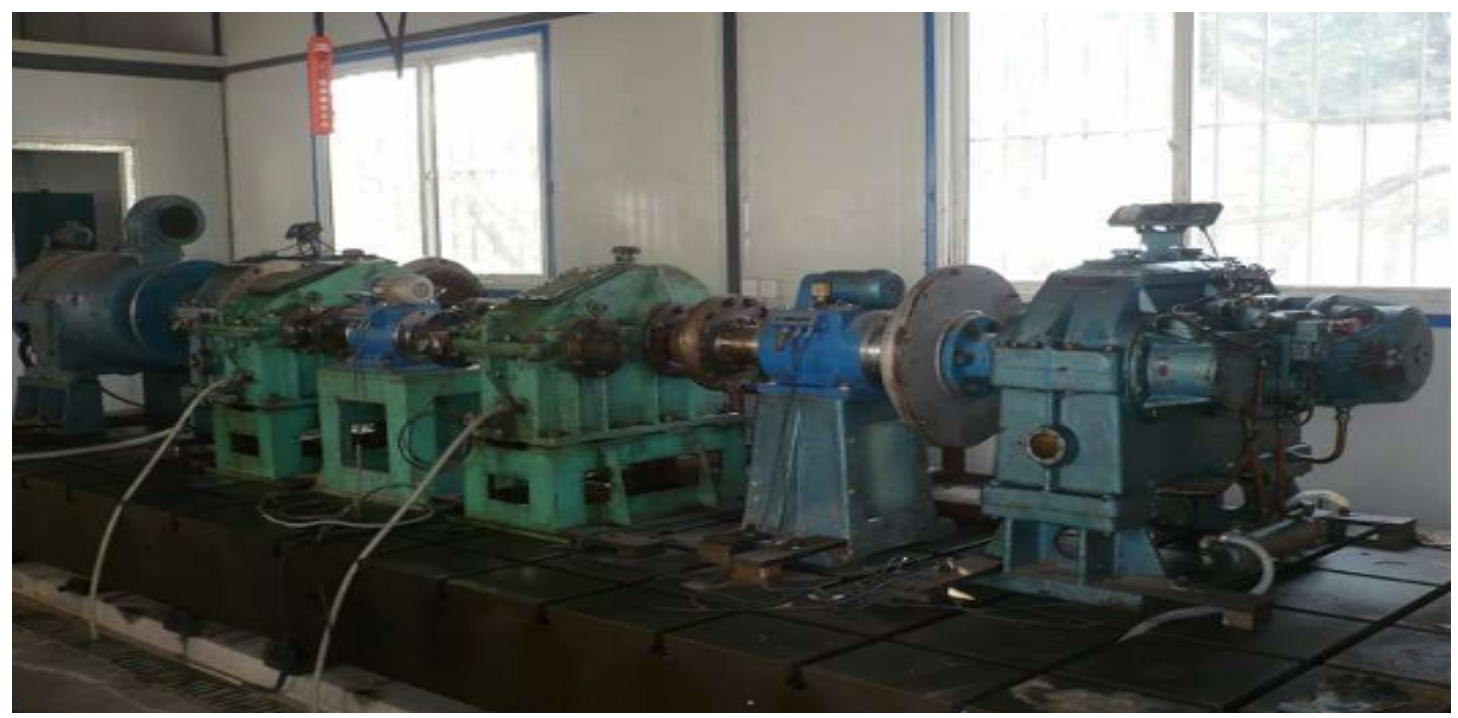

Fig. (21). Hydraulic loading test bench of helical gear.

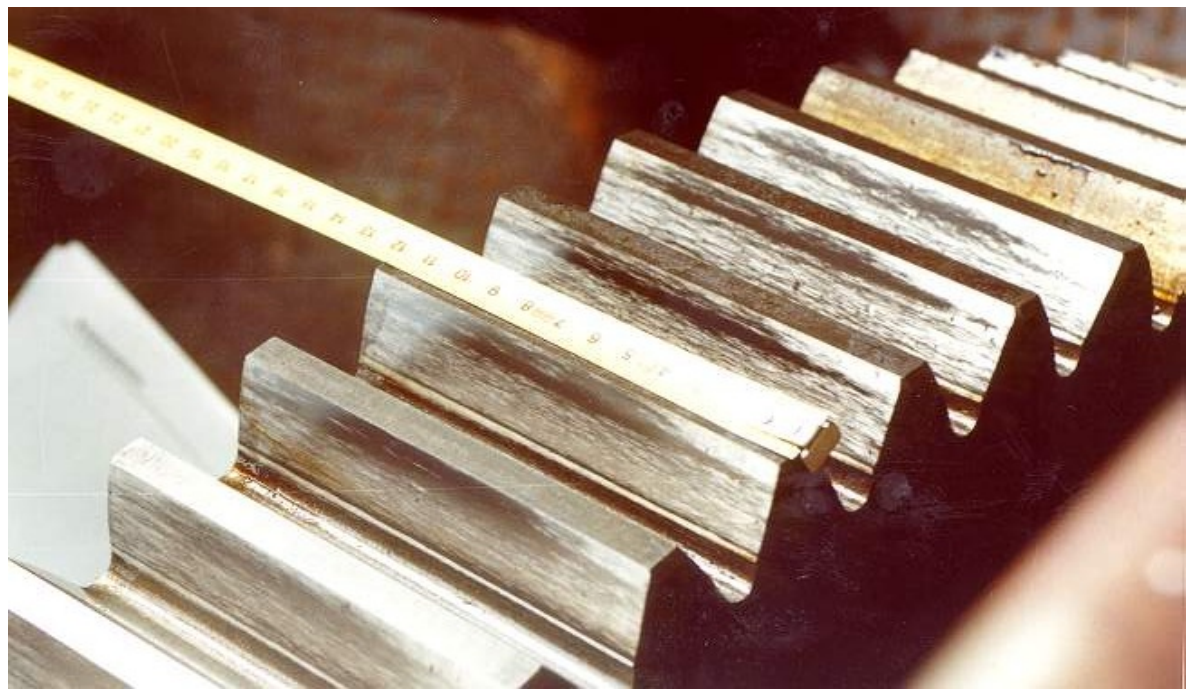

Fig. (22). A locomotive tooth surface after running 1 million kilometers.

key technology of locomotive transmission system design is deeply studied in this paper. The concrete conclusions are as follows:

(1) The bending fatigue strength of gear tooth root and impact resistance are improved through the design of single round head pre-grinding hob. At the same time, effective involute lengths and tip clearance are ensured, and the finite element model of gear root curve is established.

(2) Three-dimensional finite element model of gear transmission is established, and the bending fatigue strength and contact fatigue strength of the gear tooth are calculated for three working conditions including start, sustaining, and rapid operation.

(3) According to the results of three working operations, the modification of tooth profile is designed and finite element analysis is carried out to verify its rationality.

(4) Gear carrying capacity test verifies that the optimized transmission gear meets the design requirements, the effect is good.

\section{CONFLICT OF INTEREST}

The authors confirm that this article content has no conflict of interest.

\section{ACKNOWLEDGEMENTS}

Declared none.

\section{REFERENCES}

[1] Z. Xing, Y. Sun, X. Deng, H. Zhang, Z. Yu, and Y. Zhang, "Survey on Traction Gear Design of Electric Locomotive Mechanical Transmission", vol. 11, pp.41-47, 2011.

[2] S. Sankar, and M. Nataraj, "Profile modification-a design approach for increasing the tooth strength in spur gear", Int $J A d v$ Manuf Techno, vol. 55, pp.1 -10, 2011.

[3] S. He, R. Gunda, and R. Singh, "Effect of sliding friction on the dynamics of spur gear pair with realistic time-varying stiffness", Journal of Sound and Vibration, vol.301, pp. 927-949, 2007.

[4] S. Li, "Finite element analysis for contact strength and bending strength of a pair of spur gear with machining errors, assembly 
errors and tooth modifications", Mechanism and Machine Theory, vol.42, pp. 88-114, 2007.

[5] H. Sun, and Z. Chen, "Mechanical theory", Sixth Edition, Beijing: Higher Education Press, 2003.

[6] X. Wu, "The Gear Engagement Principle", Xi 'an JiaoTong University Press, 2009.

[7] M. Wang, "Study on Involutes Gear Profile Modification Based on Contact Finite Element Analysis", Dalian: Dalian University of Technology, 2007.

[8] G. Liu, and R. G. Parker, "Impact of tooth friction and itsbending effect on gear dynamics", Journal of Sound and Vibration, vol.320, pp. 1039-1063, 2009

[9] T. Kiekbusch, D. Sappok, B. Sauer, and I. Howard, "Calculation of the Combined Torsional Mesh Stiffness of Spur Gears with Two- and Three-Dimensional Parametrical FE Models", Journal of Mechanical Engineering, vol. 57, pp.810-818, 2011.

[10] Y. Wu, J. Wang, Q. Han, and Q. Li, "Tooth Profile Modification of Helical Gears and Experimental Study based on Finite Element Contact Analysis", Journal of Aerospace Power, vol. 26, pp. 409415, 2011.

[11] Y. Wu, J. Wang, and Q. Han, "Static/dynamic contact FEA and experimental study for tooth profile modification of helical gears", Journal of Mechanical Science and Technology, vol. 26 no. 5, pp. 1409 1417, 2012.

[12] X. Kong, M. Kang, X. Fei, and W. Liu, "Research on tooth profile modification of involute helical gear with high speed", Modern Manufacturing Engineering, vol.06, pp.105-110, 2013.

(c) Shi and He; Licensee Bentham Open.

This is an open access article licensed under the terms of the (https://creativecommons.org/licenses/by/4.0/legalcode), which permits unrestricted, non-commercial use, distribution and reproduction in any medium, provided the work is properly cited. 